\title{
Leprosy in Saudi Arabia, 1986-89
}

\author{
M A IBRAHIM, * M N KORDY, * A H AIDEROUS $\dagger$ \\ \& A BAHNASSY* \\ * Department of Community Medicine and Primary Health Care, \\ College of Medicine and Allied Health Sciences, King Abdulaziz \\ University, PO Box 6615, Jeddah 21452, Saudi Arabia; and †Ibn \\ Sina Hospital, Ministry of Health, Hadda, Saudi Arabia
}

Accepted for publication 2 May 1990

Summary This study on leprosy includes information obtained from the Ibn Sina Hospital, a specialized centre established 27 years ago for treatment and management of the disease in Saudi Arabia. A total of 792 patients with leprosy were reported during the period of the study (1986-89). A steady decline was observed in the number of patients reported: $432(54.55 \%)$ were non-Saudi and $360(45 \cdot 45 \%)$ were Saudi. Patients were reported from a total of 22 different countries. The majority of the non-Saudi patients were from the Yemen, 286 $(36 \cdot 11 \%)$. The male-to-female ratio was $3 \cdot 83: 1$. The age groups comprised: 133 $(16.79 \%), 51$ to $80 ; 575(72.60 \%), 21$ to 50 ; and $84(10.61 \%)$, under 20 years of age. The disease was classified into five categories (Ridley and Jopling classification): $295(37 \cdot 25 \%)$, lepromatous type; $238(30 \cdot 05 \%)$, tuberculoid type; $146(18.43 \%)$, borderline-tuberculoid type; 29 (3.66\%), borderline type; and $84(10.61 \%)$, borderline-lepromatous type.

Although the number of registered patients is decreasing, this trend does not suggest an overall decline in the disease in the country. It is recommended, therefore, that the services being provided to patients with leprosy must be integrated with the nationwide network of the Primary Health Care Centres to implement effective control and prevention, including health education for the general population. Furthermore, mutual agreements must be developed with adjacent countries to study the geographic distribution of the disease.

\section{Introduction}

In Saudi Arabia it is estimated that roughly 6000 cases of leprosy occur in the population of approximately 10 million. ${ }^{1,2}$ Most of the cases have been reported from the southern and western regions of the country. ${ }^{3-5}$ At the time this study was compiled, 2200 patients with leprosy had received treatment at the Ibn Sina Hospital in Hadda, located about 35 
$\mathrm{km}$ from Jeddah. This Institution, established 27 years ago, is the only facility in Saudi Arabia for the treatment of leprosy.

Beginning in 1985, an infectious and communicable disease case reporting system was established by the Ministry of Health, which also required that all patients with leprosy identified elsewhere in Saudi Arabia be reported or transferred to the Ibn Sina Hospital for registration, treatment, and rehabilitation. Since then, records (including a treatment register and an individual patient file, modified from the OMSLEP recording and reporting system for patients with leprosy that provides all the necessary information for patient evaluation) have been maintained. ${ }^{6}$ During the study period, about 792 patients registered for treatment, rehabilitation, and follow up at the Ibn Sina Hospital.

This study includes information on the patients who entered Saudi Arabia from the southern borders (Yemen), solely for specialized treatment at the Ibn Sina Hospital. In addition, a considerable expatriate population exists in the country. Patients from this population who have developed leprosy are also reported. This study explores the implication and significance of the number of patients with leprosy in the Saudi and nonSaudi population.

\section{Subjects and methods}

The subjects of this study were all patients with leprosy reported to the Ibn Sina Hospital during the period of 1986-89. The total number of reported patients was 792, which included both sexes as well as Saudi and non-Saudi patients.

Medical records at Ibn Sina Hospital were scrutinized and information regarding age, sex, nationality, area of residents, year of registry, as well as type of disease was obtained. ${ }^{7}$ Although the 792 patients were reported at the Ibn Sina Hospital for the first time in the year shown, not all of them had been diagnosed during that year. Some of the patients had been diagnosed earlier elsewhere, and for various reasons had not been reported until the year in question. The majority of these previously unreported patients involved expatriates who had been admitted to Saudi Arabia with known disease. In addition, the majority of the $286(36 \cdot 11 \%)$ patients from Yemen came to Saudi Arabia for treatment and rehabilitation for their disease and deformities at the Ibn Sina Hospital. The data were collected only for the registered patients during the study period. The patients were categorized according to the Ridley and Jopling classification into five types: lepromatous, tuberculoid, borderline-tuberculoid, borderline, and borderline-lepromatous. ${ }^{7}$ The data were transferred to coding sheets and entered into computer files. Data were analysed using an IBM microcomputer; SPSSPC + software package was used to analyse the data.

\section{Results}

This study showed that the number of patients with leprosy registered during the last four years (1986-1989) has declined. A high of 268 patients with leprosy was reported in 1986 and a low of 158 in 1988, with an increase to 169 patients reported in 1989 (Table 1). The average number of patients admitted was 198 per year.

Of the total 792 patients reported with leprosy during 1986 to 1989 in Saudi Arabia, 
Table 1. Reported cases of leprosy in Saudi Arabia (1986 to November 1989)

\begin{tabular}{llc}
\hline & \multicolumn{2}{c}{ Patients registered } \\
\cline { 2 - 3 } Year & No. & $\%$ \\
\hline 1986 & 262 & $33 \cdot 08$ \\
1987 & 203 & $25 \cdot 63$ \\
1988 & 158 & $19 \cdot 95$ \\
1989 & 169 & $21 \cdot 34$ \\
\hline Total & 792 & $100 \cdot 00$ \\
\hline
\end{tabular}

Table 2. Distribution of patients with leprosy in Saudi Arabia by gender (1986 to November 1989)

\begin{tabular}{|c|c|c|c|c|c|}
\hline \multirow[b]{2}{*}{ Year } & \multicolumn{2}{|c|}{ Male } & \multicolumn{2}{|c|}{ Female } & \multirow[b]{2}{*}{ Total } \\
\hline & No. & $\% *$ & No. & $\% \dagger$ & \\
\hline 1986 & 217 & $34 \cdot 55$ & 45 & $27 \cdot 44$ & 262 \\
\hline 1987 & 165 & $27 \cdot 27$ & 38 & $23 \cdot 17$ & 203 \\
\hline 1988 & 122 & $19 \cdot 43$ & 36 & 21.95 & 158 \\
\hline 1989 & 124 & $19 \cdot 74$ & 45 & $27 \cdot 44$ & 169 \\
\hline Total & 628 & $100 \cdot 00$ & 164 & $100 \cdot 00$ & 792 \\
\hline $\begin{array}{r}* \mathrm{P} \\
1989 . \\
\dagger \mathrm{P} \\
1989 .\end{array}$ & enta & $\begin{array}{l}\text { of tot } \\
\text { of tot }\end{array}$ & les, & 986 to & ember \\
\hline
\end{tabular}

Table 3. Age distribution of patients with leprosy in Saudi Arabia (1986 to November 1989)

\begin{tabular}{lrc}
\hline $\begin{array}{l}\text { Age range } \\
\text { (years) }\end{array}$ & No. & $\%$ \\
\hline$<20$ & 84 & $10 \cdot 61$ \\
$21-50$ & 575 & $72 \cdot 60$ \\
$51-80$ & 133 & $16 \cdot 79$ \\
\hline Total & 792 & $100 \cdot 00$ \\
\hline
\end{tabular}

$628(79 \cdot 29 \%)$ were males and $164(20 \cdot 71 \%)$ were females, for a ratio of $3 \cdot 83: 1$ (Table 2$)$. Of these patients, $133(16 \cdot 79 \%)$ were 51 to 80 years old, $575(72 \cdot 60 \%)$ were 21 to 50 years old, and $84(10 \cdot 61 \%)$ were under 20 years old (Table 3$)$. Of those under 20 , nine $(1 \cdot 14 \%)$ were less than ten years old. None of the registered patients were excluded from the study. 


\section{CLASSIFICATION OF DISEASE}

According to the Ridley and Jopling classification of disease, the lepromatous type had the highest number of patients 295 (37.25\%) compared to the other types. Classification breakdowns for other categories were: tuberculoid type, 238 (30.05\%); borderlinetuberculoid, 146 (18.43\%); borderline type, 29 (3.66\%); and borderline-lepromatous type, 84 (10.61\%) (Table 4$)$.

\section{REGIONAL DISTRIBUTION IN PATIENTS WITH LEPROSY}

The largest number of patients, $306(60 \cdot 47 \%)$ was from the western region. The southern region had the next largest number of reported cases, $116(22.92 \%)$. The number of patients reported from the central region was $44(8.69 \%)$; those reported from the northern region were $31(6 \cdot 13 \%)$; and the remaining nine $(1 \cdot 79 \%)$ were reported from the eastern region (Table 5). These data demonstrate that the disease may be concentrated in the south-western region of the country.

\section{SAUDI VERSUS NON-SAUDI PATIENTS WITH LEPROSY}

Classifying the patients into Saudi and non-Saudi groups, the results of this study showed more non-Saudi than Saudi patients. Of the 792 reported patients, 432 (54.55\%) were

Table 4. Classification of disease in patients with leprosy reported in Saudi Arabia (1986 to November 1989)

\begin{tabular}{lrr}
\hline Type of disease & No. & $\%$ \\
\hline Lepromatous & 295 & $37 \cdot 25$ \\
Tuberculoid & 238 & $30 \cdot 05$ \\
Borderline-tuberculoid & 146 & 18.43 \\
Borderline & 29 & 3.66 \\
Borderline-lepromatous & 84 & $10 \cdot 61$ \\
\hline Total & 792 & $100 \cdot 00$ \\
\hline
\end{tabular}

Table 5. Distribution of patients with leprosy in Saudi Arabia by region* (1986 to November 1989)

\begin{tabular}{lrr}
\hline Region & No. & \multicolumn{1}{c}{$\%$} \\
\hline Western & 306 & $60 \cdot 47$ \\
Southern & 116 & 22.92 \\
Central & 44 & $8 \cdot 69$ \\
Northern & 31 & $6 \cdot 13$ \\
Eastern & 9 & $1 \cdot 79$ \\
\hline Total & 506 & $100 \cdot 00$ \\
\hline
\end{tabular}

* Does not include 286 Yemeni patients. 
Table 6. Source of patients with leprosy reported in Saudi Arabia, native and foreign born (1986 to November 1989)

\begin{tabular}{lrrrrrrrr}
\hline & \multicolumn{2}{c}{ Saudi } & & \multicolumn{2}{c}{ Non-Saudi } & & \multicolumn{2}{c}{ Total } \\
\cline { 2 - 3 } \cline { 8 - 9 } Year & No. & $\% *$ & & No. & $\%$ & & No. & $\% *$ \\
\hline 1986 & 127 & 16.04 & & 135 & 17.05 & & 262 & 33.08 \\
1987 & 95 & 11.99 & & 108 & 13.64 & & 203 & 25.63 \\
1988 & 64 & 8.08 & & 94 & 11.87 & & 158 & 19.95 \\
1989 & 74 & 9.34 & & 95 & 11.99 & & 169 & 21.34 \\
\hline Total & 360 & 45.45 & & 432 & 54.55 & & 792 & 100.00 \\
\hline
\end{tabular}

* Percentage of total patients reported (1986 to November 1989).

non-Saudi and $360(45 \cdot 45 \%)$ were Saudi (Table 6). The non-Saudi patients came into Saudi Arabia from 22 countries. The Yemenis contributed the largest number of patients reported among the non-Saudi group-286 (36.11\%) of the total. The second largest group, 95 (12\%), was reported from the Asian subcontinent. Lastly, 51 (6.44\%) were reported from Africa (Table 7). The total number of Saudi patients declined from 127 in 1986 to 64 in 1988, then increased to 74 in 1989, whereas the non-Saudi patients declined from 135 in 1986 to 94 in 1988, then increased by one patient in 1989. The overall total demonstrates that the trend of the patients reported with leprosy during the study period was declining, with a slight increase in the number of patients reported in 1989 (Table 6).

Table 7. Distribution of patients with leprosy in Saudi Arabia by nationality (1986 to November 1989)

\begin{tabular}{lrr}
\hline Country & No. & \multicolumn{1}{c}{$\%$} \\
\hline Saudi Arabia & 360 & $45 \cdot 45$ \\
Yemen & 286 & $36 \cdot 11$ \\
India & 40 & $5 \cdot 05$ \\
Pakistan & 24 & $3 \cdot 03$ \\
Egypt & 16 & $2 \cdot 02$ \\
Bangladesh & 15 & $1 \cdot 89$ \\
Sudan & 10 & $1 \cdot 26$ \\
Indonesia & 9 & $1 \cdot 14$ \\
Somalia & 4 & $0 \cdot 51$ \\
Burma & 4 & $0 \cdot 51$ \\
Eritrea & 3 & $0 \cdot 38$ \\
Mali & 3 & $0 \cdot 38$ \\
Sri-lanka & 3 & $0 \cdot 38$ \\
Ethiopia & 3 & $0 \cdot 38$ \\
Other & 12 & $1 \cdot 51$ \\
\hline Total & 792 & $100 \cdot 00$ \\
\hline
\end{tabular}




\section{Discussion}

Before 1985, medical records and a case registry were not properly maintained at Ibn Sina Hospital, hence an accurate follow-up of patients was not available. A suspected diagnosis of leprosy is the only qualification for admission to the Ibn Sina Hospital. Anyone who has or is suspected of having leprosy, and comes to the hospital requesting care for an illness, is entitled to admission. This liberal admission policy applied not only to Saudi patients, but also to all expatriates, including those who are in the country on a visitor's visa or pilgrimage visa, and aliens residing in the country illegally. Any expatriate may be hospitalized for treatment, because treatment is considered to be a control measure instituted to decrease or eliminate hazards these expatriates may present to the Saudi Arabian public health.

Accurate records of the 2200 patients who received treatment at the Ibn Sina Hospital before 1986 were not available; therefore, comparisons could not be made to reflect the average annual change of reported patients with leprosy in the country. Previous studies have not demonstrated long-term comparisons. ${ }^{3-5}$ A recent report from the eastern region concluded that the disease was rare in this region. ${ }^{5}$ In our study, patients reported from the southeastern region remain the highest, and those reported from the eastern region the least, which is in concordance with previous reports. ${ }^{3,4}$

This study showed a decline in the number of Saudi patients registered during the past four years; however, an increase is expected in the number of reported patients over the next few years. This is to be attributed to the recently established nationwide primary health services network of the Ministry of Health. It is also expected that the Ministry of Health will adopt the World Health Organisation (WHO) recommendations to integrate the primary health care service providers, and involve them in management of patients with leprosy, as well as develop awareness in the community through health education. ${ }^{8,9}$ The decline in the number of non-Saudi patients is due to the stringent measures the Government has taken to screen expatriate workers before issuing them with work permits to enter the country; however, a few escape detection or may not have developed the disease at the time of entry. The other category of patients is from Yemen. The Yemeni patients contribute to the largest number of patients entering the country legitimately, either as expatriate workers or specifically to seek medical treatment. Accurate data were not available on the contacts with Saudi as well as non-Saudi patients.

\section{Conclusions}

The prevalence of patients with leprosy in Saudi Arabia remains less than in the neighbouring countries. With improved health services being offered to the community through the Primary Health Care Centres of the Ministry of Health, proposed integration of the management of diagnosed cases at this level, a further decline is expected in patients being reported to the Ibn Sina Hospital. The patient registration system, therefore, must be enforced rigorously to identify new patients and their contacts to promote efficient control programmes nationwide.

Although sincere efforts are made by the personnel of the Ibn Sina Hospital to maintain contact with patients throughout the duration of their treatment, loss to follow- 
up remains a disadvantage for the programme. Saudi patients may return to their town and continue receiving treatment, either at the Primary Health Care Centre or in a private medical facility, whereas non-Saudi patients may return to their country of origin.

So far, no regional or nationwide surveys have been conducted to study the magnitude of the disease in Saudi Arabia, nor are there any established programmes through the government or non-government organizations for the control of leprosy in Saudi Arabia. The recent representation of Saudi Arabia in the international activities of the WHO for the prevention and control of leprosy, however, has provided an incentive to develop such programmes in the country.

\section{Recommendations}

Based on the results of this study, it is recommended that:

1 A surveillance system be developed to detect patients with leprosy using the primary health care centres.

2 Specific guidelines be established according to the WHO requirements to integrate primary health services.

\section{Acknowledgments}

The authors thank the Ibn Sina Hospital physicians for their assistance in collecting and compiling the data for this study, and Gae O Decker-Garrad for editorial assistance and preparation of the manuscript.

\section{References}

1 Aiderous AH. Leprosy disability in the Kingdom of Saudi Arabia and current status of rehabilitation program. The Asian Conference on Rehabilitation of Leprosy (WHO, ILU), Kuala Lumpur, Malaysia, September 1989.

2 Noordeen SK, Bravo LL. The world leprosy situation. Rapp trimest starist sanit mond, 1986; 39: $122-8$.

3 Sebai ZH. An epidemiological study of leprosy and leprosy care in Saudi Arabia. Saudi Med J, 1980; 1(3): $133-40$.

${ }^{4}$ Sebai ZH. Health in Saudi Arabia, Vol. 1, First Edition, Tihama, Saudi Arabia, pp. 159-70, 1985.

5 Al Sogair SM, Ellahbadi SL, Namnyak SS. Leprosy in the Eastern Province of Saudi Arabia. Saudi Med J, 1989: 10(1): 48-53.

${ }^{6}$ Lechat MF, et al. OMSLEP recording and reporting system for leprosy patients. Brussels, Epidemiology Unit, School of Public Health, Catholic University of Louvain, p. 117, 1987.

7 Ridley DS, Jopling WH. Classification of leprosy according to immunity. A five group system. Int J Lepr, 1966; 34: 255-73.

8 WHO. Expert Committee on Leprosy-Sixth Report. WHO Tech Series, p. 768, Geneva, 1988.

9 A Guide to Leprosy Control, Second Edition, WHO, Geneva, 1988. 